\title{
SISTEM INFORMASI GEOGRAFIS PEMETAAN KERUSAKAN JALAN DI KABUPATEN MALANG MENGGUNAKAN METODE K-MEANS
}

\author{
Tutut Suryani, Ahmad Faisol, Nurlaily Vendyansyah \\ Program Studi Teknik Informatika S1, Fakultas Teknologi Industri \\ Institut Teknologi Nasional Malang, Jalan Raya Karanglo km 2 Malang, Indonesia \\ tttsuryani@gmail.com
}

\begin{abstract}
ABSTRAK
Jalan adalah sarana transportasi darat yang berperan penting dalam sektor perhubungan untuk menghubungkan antara satu kota dengan kota lainnya, antara kota dengan desa, antara satu desa dengan desa lainnya. Adanya kerusakan jalan akan mempengaruhi keamanan dan kenyamanan pengguna jalan. Banyak terdapat kerusakan jalan di Kabupaten Malang yang masih belum diperbaiki yang disebabkan oleh terbatasnya informasi kerusakan jalan sehingga dibutuhkan laporan dari warga mengenai kerusakan jalan yang ada disekitarnya. Laporan dari warga dapat mempermudah Pemerintah Kabupaten untuk menindaklanjuti perbaikan jalan. Dengan adanya permasalahan tersebut maka dibuat sistem informasi geografis pemetaan kerusakan jalan dengan harapan pemerintah dapat mengelompokkan tingkat kerusakan jalan menggunakan metode clustering di Kabupaten Malang yang meliputi Kecamatan Lawang, Kecamatan Singosari, Kecamatan Karangploso, dan Kecamatan Dau. Salah satu metode clustering yang digunakan pada sistem ini adalah metode k-means. Data yang diolah dalam penelitian ini yaitu data kerusakan jalan dari Dinas Bina Marga Kabupaten Malang. Sistem dibuat menggunakan website dengan framework Codeigniter, sedangkan untuk pemetaan kerusakan jalan pada penelitian ini menggunakan OpenStreetMap. Berdasarkan hasil pengujian akurasi metode menunjukkan bahwa metode k-means yang diterapkan pada website ini sudah tepat dengan tingkat presentase kecocokannya $100 \%$. Perbandingan hasil clustering k-means pada program dan Dinas Bina Marga sama-sama menunjukkan jumlah $\mathrm{C} 1$ $($ Ringan $)=221$ data, C2 $($ Sedang $)=24$, dan C3 (Berat $)=65$ data. Sedangkan pada pengujian metode black box yang dilakukan terhadap sistem informasi geografis pemetaan kerusakan jalan di Kabupaten Malang ini dapat disimpulkan bahwa dalam pengujian tidak ditemukan kesalahan pada sistem sehingga fungsionalitas sistem berjalan sesuai dengan perancangan.
\end{abstract}

Kata Kunci : Sistem Informasi Geografis, Pemetaan, Kerusakan Jalan, Clustering, K-Means, Kabupaten Malang.

\section{PENDAHULUAN}

Jalan adalah sarana transportasi darat yang berperan penting dalam sektor perhubungan untuk menghubungkan antara satu kota dengan kota lainnya, antara kota dengan desa, antara satu desa dengan desa lainnya. Adanya kerusakan jalan akan mempengaruhi keamanan dan kenyamanan pengguna jalan. Faktor yang menyebabkan terjadinya kerusakan jalan antara lain air, perubahan suhu, cuaca, temperatur udara, material konstruksi perkerasan, kondisi tanah dasar yang tidak stabil, proses pemadatan di atas lapisan tanah dasar yang kurang baik, kapasitas muatan kendaraan yang berlebihan, dan meningkatnya volume kendaraan. [1]

Kenyataan dilapangan masih banyak kerusakan jalan di kabupaten malang yang masih belum diperbaiki terutama di Kecamatan Lawang, Kecamatan Singosari, Kecamatan Karangploso, dan Kecamatan Dau. Adanya kerusakan jalan ini dapat menghambat aktivitas masyarakat terutama dalam sector perhubungan. Masalah ini disebabkan oleh terbatasnya informasi kerusakan jalan sehingga dibutuhkan laporan dari warga mengenai kerusakan jalan yang ada disekitarnya. Laporan dari warga dapat mempermudah pemerintah Kabupaten untuk menindaklanjuti perbaikan jalan. Untuk saat ini masih belum ada pelaporan system informasi geografis mengenai kerusakan jalan di Kabupaten Malang yang dapat diakses oleh masyarakat secara online.

Oleh karena itu penulis bermaksud membuat sistem informasi geografis pemetaan kerusakan jalan oleh warga yang diharapkan Pemerintah dapat mengelompokkan tingkat kerusakan jalan di Kabupaten Malang menggunakan metode k-means. Metode kmeans adalah metode yang dapat digunakan untuk mengelompokkan tingkat kerusakan jalan sehingga pemerintah mengetahui tingkatan rusak berat dapat ditangani terlebih dahulu.

\section{TINJAUAN PUSTAKA}

\subsection{Penelitian Terdahulu}

Penelitian yang di lakukan sebelumnya merupakan penelitian mengenai pembuatan system informasi geografis pemetaan jalan di desa. Informasi mengenai jalan desa juga merupakan hal yang penting, namun pendataan masih jarang dilakukan. Hal tersebut dikarenakan jumlah jalan desa yang banyak dan cara mendatanya masih dengan cara manual yang mengakibatkan sulitnya pengumpulan data secara efisien, sehingga diperlukannya sebuah system untuk melakukan pendataan jalan agar dapat lebih cepat. Pengolahan data pada data master dapat 
dilakukan oleh admin. Hasil dari pendataan jalan desa ini memberikan informasi bagi pengguna tentang nama jalan, panjang jalan, jenis permukaan jalan, dan kondisi jalan. [2]

Penelitian Selanjutnya mengangkat masalah evaluasi kerusakan ruas jalan Kalimas Baru Kota Surabaya. Penelitian ini bertujuan untuk mengetahui nilai kondisi perkerasan jalan, jenis kerusakan, dan alternatif penanganan dengan menyesuaikan kerusakan yang terjadi pada ruas Jl. Kalimas Baru. Penelitian ini menggunakan metode metode diskriptif kualitatif dan metode diskriptif kuantitatif. Kerusakan yang terjadi pada ruas Jl. Kalimas Baru menunjukkan terdapat 6 macam kerusakan. Jenis kerusakan tersebut adalah Retak kulit buaya, alur, tambalan, pelapukan dan butiran lepas, retak memanjang, dan yang terakhir amblas. [3]

Selanjutnya penelitian yang mengangkat masalah saat ini Dinas Pekerjaan Umum Kabupaten Serang masih kesulitan dalam menyajikan informasi data spasial dalam bentuk peta digital, masih kesulitan dalam melakukan pemeliharaan data pada kondisi jalan, dan masih belum ada publikasi data kondisi jalan sehingga membuat masyarakat sulit memperoleh informasi tentang kondisi jalan tersebut. Salah satu solusi untuk menyajikan data spasial tersebut yaitu menggunakan Sistem Informasi Geografis [4]

Penelitian selanjutnya mengenai penerapan permodelan spasial pada system informasi geografis tenaga kesehatan Kabupaten Malang. Di wilayah Kabupaten Malang terjadi pembengkakan kebutuhan pelayanan kesehatan yang masih memiliki ketidakseimbangan antara sarana pelayanan kesehatan dan kebutuhan pelayanan, sehingga diperlukan pemerataan sarana serta tenaga kesehatan yang memadai. Penelitian ini bertujuan untuk memonitor jumlah penyebaran tenaga kesehatan, sehingga pemerintah daerah secara visual dapat melihat penumpukan atau kekurangan tenaga pada puskesmas di suatu kecamatan. [5]

Berikutnya penelitian mengenai pengelompokkan banyaknya desa/kelurahan menurut upaya antisipasi/mitigasi bencana alam menggunakan metode clustering kmeans. Indonesia merupakan Negara yang sangat rawan dengan bencana alam. Penanggulangan bencana alam atau mitigasi adalah upaya berkelanjutan untuk mengurangi dampak bencana terhadap manusia dan harta benda. Penelitian ini mengangkat masalah mengenai pengelompokan desa/kelurahan menurut upaya antisipasi/mitigasi bencana alam menurut provinsi dimana proses algoritma yang dilakukan adalah clustering. Hasil dari cluster dapat dijadikan masukan bagi pemerintah agar provinsi yang masuk kedalam cluster rendah mendapat perhatian lebih dalam peningkatan sarana dan prasarana upaya antisipasi bencana. Clustering ini dibagi menjadi tiga cluster yaitu sarana kesehatan tertinggi, sarana kesehatan sedang dan sarana kesehatan rendah. [6]

\subsection{Sistem Informasi Geografis}

Sistem informasi geografis adalah system computer yang digunakan untuk mengelola, menganalisis, dan menyebarkan informasi geografis yang berkaitan dengan tata letak keruangan dan informasi-informasi yang berhubungan dengan permukaan bumi. SIG memiliki banyak manfaat salah satunya adalah memberikan kemudahan kepada para pengguna untuk menentukan kebijaksanaan yang akan diambil. Dengan adanya system informasi geografis diharapkan dapat memudahkan pemetaan lahan dan pemetaan jalan. [7]

\subsection{Jalan}

Peraturan Pemerintah Nomor 34 Tahun 2006 menyatakan bahwa jalan adalah sarana transportasi darat yang berperan penting dalam sector perhubungan untuk menghubungkan antara satu kota dengan kota lainnya, antara kota dengan desa, antara satu desa dengan desa lainnya. Jalan berada diatas permukaan tanah dan air serta dibawah permukaan tanah dan air yang digunakan untuk kegiatan berlalu lintas. Berikut klasifikasi tingkat kerusakan jalan :

1. Jalan dalam kondisi baik

2. Jalan dalam kondisi sedang

3. Jalan dalam kondisi rusak ringan

4. Jalan dalam kondisi rusak berat

\subsection{Kerusakan Jalan}

Menurut Bina Marga No. 03/MN/B/1983 tentang Manual Pemeliharaan Jalan, jenis kerusakan jalan dibedakan 6 kategori yaitu Retak (cracking), Distorsi, Cacat permukaan (disintegration), Pengausan (polished aggregate), Kegemukan (bleeding or flushing) dan Penurunan pada bekas penanaman utilitas. Pada penelitian ini lebih difokuskan pada keretakan jalan (cracking).

\subsection{Metode K-Means}

Metode K-means adalah metode analisa data yang digunakan untuk mengelompokkan data yang sudah ada ke dalam beberapa kelompok, dimana data dalam satu kelompok mempunyai karakteristik yang sama dengan lainnya dan data yang ada di dalam kelompok lain mempunyai karakteristik yang berbeda.

[8] Algoritma clustering dapat dikelompokkan ke dalam kelompok besar sebagai berikut :

a. Partitioning algorithms

b. Hierarchy algorithms

c. Density-based

d. Grid-based

e. Model-based

Adapun langkah-langkah algoritma K-Means, antara lain sebagai berikut :

a. Menghitung jumlah data (p)

b. Menentukan jumlah cluster (k)

c. Menentukan centroid awal

d. Menghitung jarak data dengan centroid 1 dan centroid 2 menggunakan rumus (2.1) berikut : 
$d(x, y)=\sqrt{\left(x_{1}-y_{1}\right)^{2}+\left(x_{2}-y_{2}\right)^{2}+\ldots+\left(x_{m}-y_{m}\right)^{2}}$

Keterangan :

- d(x,y) adalah Euclidean Distance

- (x) merupakan koordinat object

- (y) merupakan koordinat centroid

e. Mengelompokkan data sesuai cluster berdasarkan jarak terpendek

f. Menghitung centroid berikutnya / rata-rata tiap cluster

g. Apabila hasil perhitungan centroid baru pada iterasi terakhir sama dengan iterasi sebelumnya maka iterasi dihentikan.

\subsection{Kabupaten Malang}

Kabupaten Malang adalah kabupaten yang terletak pada dataran tinggi sehingga memiliki udara yang sejuk. Terdapat 33 Kecamatan di Kabupaten Malang, antara lain Bululawang, Godanglegi, Tajinan, Turen, Kepanjen, Pagelaran, Pakisaji, Singosari, Lawang, Karangploso, Dau, Pakis, Dampit, Sumberpucung, Kromengan, Pagak, Kalipare, Donomulyo, Bantur, Ngajum, Gedangan, Sumbermanjing Wetan, Wagir, Wonosari, Pujon, Ngantang, Kasembon, Poncokusumo, Jabung, Wajak, Ampelgading, dan Tirtoyudo [9]

\subsection{Dinas Bina Marga Kabupaten Malang}

Dinas Bina Marga Kabupaten Malang adalah salah satu organisasi sector public yang bertugas menangani jalan, jembatan dan bangunan pelengkapnya serta pembinaan dan pengawasan terhadap pemanfaatan Ruang Milik Jalan yang terletak di Jalan Trunojoyo No.6, Kedungpedaringan, Kepanjen, Ngadiluwih, Kedungpedaringan, Kec. Kepanjen, Malang, Jawa Timur 65163[10]

\subsection{Pemetaan}

Pemetaan merupakan proses penyajian informasi muka Bumi yang berupa fakta, dunia nyata, baik bentuk permukaan buminya maupun sumber daya alamnya, berdasarkan skala peta, sistem proyeksi peta, serta simbol-simbol dari unsur muka Bumi yang disajikan. Pada dasarnya peta adalah sebuah data yang didesain untuk mampu menghasilkan sebuah informasi geografis melalui proses pengorganisasian dari kolaborasi data lainnya yang berkaitan dengan bumi untuk menganalisis, memperkirakan dan menghasilkan gambaran kartografi. Informasi ruang mengenai bumi sangat kompleks. [11]

\subsection{Metode Black Box}

Black Box Testing merupakan pengujian yang dilakukan hanya dengan mengamati hasil eksekusi melalui data uji dan memeriksa fungsional dari perangkat lunak. Pengujian ini tujuannya untuk mengetahui bahwa bagian-bagian dalam sistem aplikasi telah benar menampilkan sesuai dengan perancangan program. Pengujian black box menitik beratkan pada fungsi system [12]

\section{METODE PENELITIAN}

\subsection{Analisis Kebutuhan}

Pada analisis system ini akan di jabarkan secara keseluruhan mengenai kebutuhan apa saja yang harus ada pada aplikasi tersebut baik secara fungsional maupun non fungsional.

\subsection{Analisis Kebutuhan Fungsional}

Pada website Sistem Informasi Geografis ini memiliki kebutuhan Fungsinonal sebagai berikut :

1. Website mampu menampilkan informasi umum di kabupaten malang

2. Website mampu menampilkan maps yang terdapat marker kerusakan jalan

3. Website mampu melaporkan informasi mengenai kerusakan jalan

4. Website mampu menampilkan data laporan kerusakan jalan yang telah diinput oleh warga

5. Website ini mampu menampilkan grafik hasil clustering

6. Website ini mampu mengelola data laporan kerusakan jalan

7. Website mampu menampilkan data kerusakan jalan di Kabupaten Malang

8. Website mampu menampilkan hasil clustering kerusakan jalan

9. Website mampu mengirim email kepada pelapor untuk verifikasi data.

10. Website mampu diakses oleh 2 level user yaitu masyarakat dan admin.

\subsection{Analisis Kebutuhan Non-Fungsional}

Pada website Sistem Informasi Geografis ini memiliki kebutuhan Non-Fungsional yaitu:

1. Website ini dapat dijalankan pada web browser

2. Website ini hanya bisa melaporkan kerusakan jalan oleh user

3. Website ini hanya bisa mengupload gambar sebesar $2 \mathrm{MB}$

4. Website ini bisa mengirim email verifikasi ketika status masih belum diproses.

5. Website ini dapat melakukan proses clustering pada kerusakan jalan menggunakan metode Kmeans.

\subsection{Struktur Menu}

Struktur menu pada sistem ini menampilkan menu-menu yang terdapat pada website. Struktur menu yang dirancang dapat dilihat seperti Gambar 3.1 


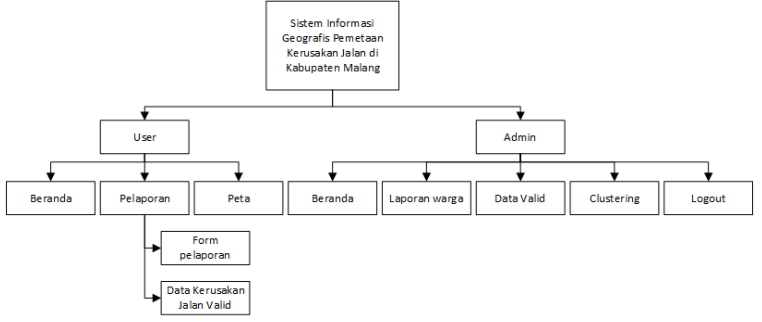

Gambar 3.1 Struktur Menu

Berdasarkan struktur menu sistem pada Gambar 3.1 terdapat 2 user level yaitu user dan admin. Pada user terdapat menu beranda untuk menampilkan halaman utama, menu pelaporan yang terdapat form pelaporan dan data kerusakan data valid, menu peta yang menampilkan pemetaan kerusakan jalan. Pada admin terdapat menu beranda untuk menampilkan data cluster dan grafik cluster, menu laporan warga untuk mengelola laporan data kerusakan jalan, menu data valid untuk mengelola data kerusakan jalan yang sudah valid, menu clustering untuk menampilkan jenis cluster pada data valid dan menu logout untuk keluar dari halaman admin.

\subsection{Blok Diagram Sistem}

Blok diagram system ini menjelaskan cara kerja sistem tersebut secara garis besar. Seperti pada Gambar 3.2

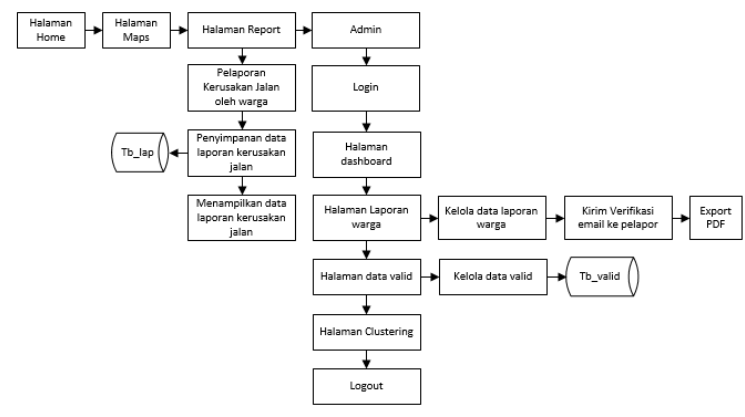

Gambar 3.2 Blok diagram sistem

Berdasarkan blok diagram system pada Gambar 3.2 diawali dengan menampilkan halaman home, halaman maps, halaman report, dan halaman admin. Pada halaman report terdapat pelaporan kerusakan jalan yang datanya akan disimpan ditabel laporan. Pada halaman admin diarahkan untuk login agar admin dapat mengelola data kerusakan jalan.

\subsection{Flowchart User}

Flowchart user ini menjelaskan proses berjalannya aplikasi bagian user. Seperti pada Gambar 3.3

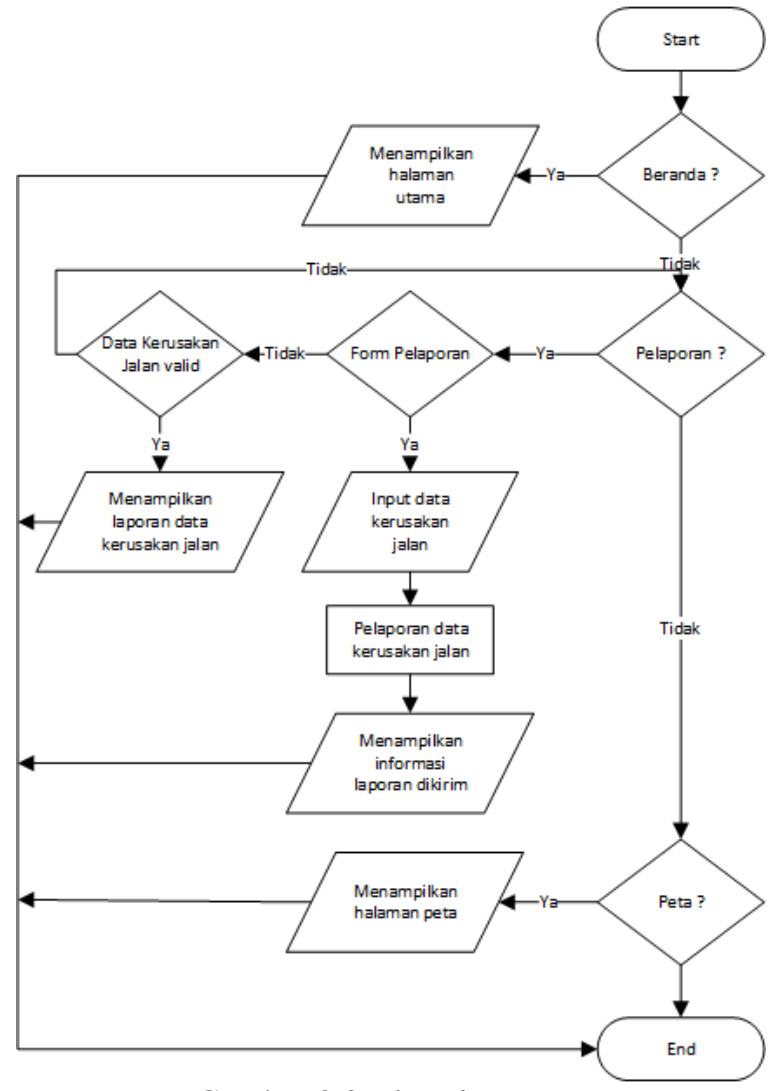

Gambar 3.3 Flowchart User

Berdasarkan flowchart user pada Gambar 3.3 diawali decision apakah user ingin mengakses beranda, jika ya maka akan tampil halaman utama apabila tidak maka masuk decision pelaporan. Apabila user ingin melaporkan kerusakan jalan maka diarahkan untuk menginputkan data kerusakan jalan apabila tidak maka masuk decision data kerusakan jalan. Pada decision data kerusakan jalan apakah user ingin mengakses data kerusakan jalan apabila iya maka menampilkan data laporan kerusakan jalan apabila tidak maka kembali ke pelaporan. Pada decision peta persebaran apakah user ingin mengakses halaman peta, jika ya maka menampilkan halaman peta persebaran apabila tidak maka program berakhir.

\subsection{Flowchart Admin}

Flowchart admin ini menjelaskan proses berjalannya aplikasi dari sistem informasi geografis pemetaan kerusakan jalan bagian admin yang telah ditunjukkan pada gambar 3.4 


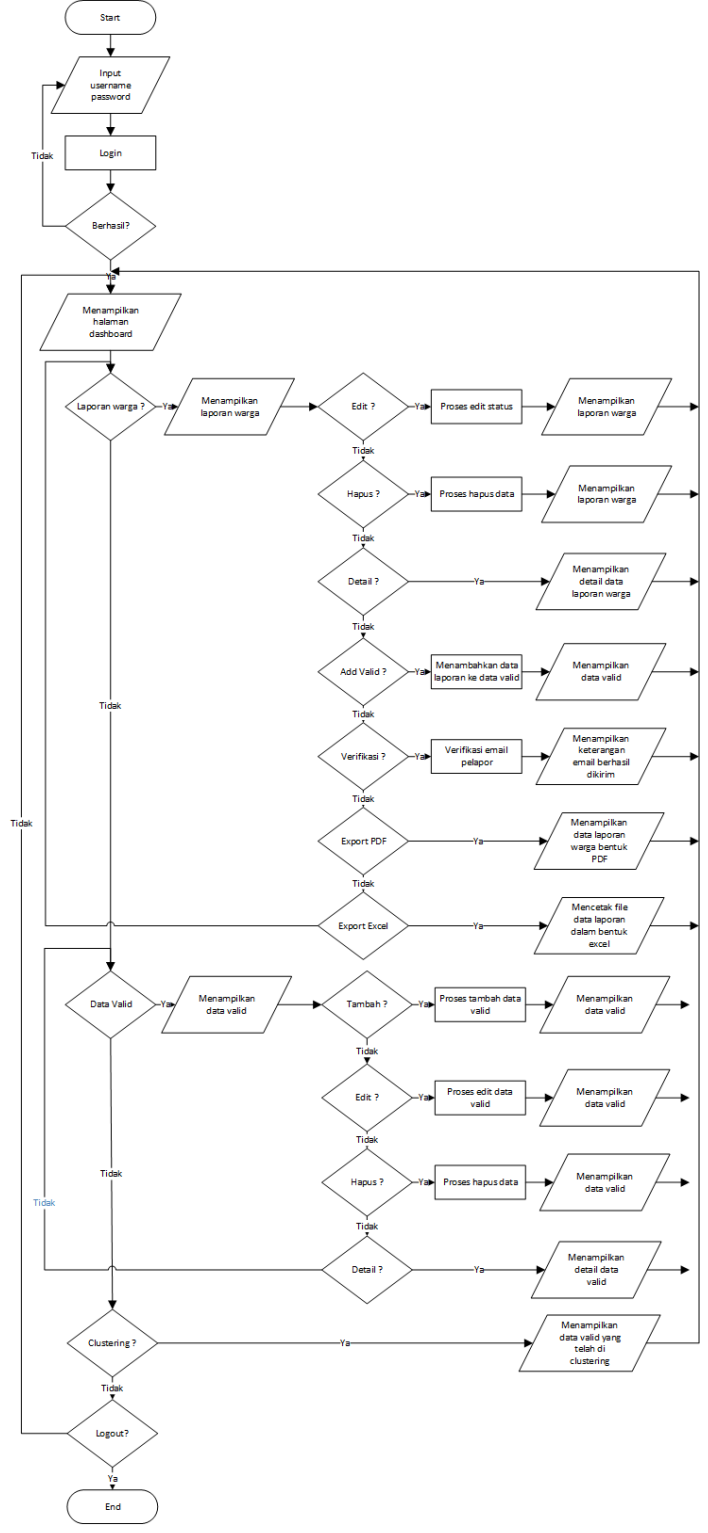

Gambar 3.4 Flowchart Admin

Berdasarkan flowchart admin pada Gambar 3.4 flowchart admin diawali halaman login dahulu untuk menginputkan username dan password. Apabila username dan password benar maka dapat menampilkan halaman dashboard admin, apabila salah maka diarahkan untuk input username dan password sampai benar. Pada laporan warga akan menampilkan data kerusakan jalan dari user dimana admin dapat mengedit status, menghapus data, menambahkan data laporan setelah valid ke database table valid secara otomatis, mengirimkan verifikasi email kepada pelapor, melakukan export data menjadi format pdf dan excel. Pada data valid akan menampilkan data yang didapatkan setelah melakukan survey dimana admin dapat melakukan proses tambah, edit, delete dan detail data kerusakan jalan. Pada navbar clustering akan menampilkan data kerusakan jalan yang disertai hasil clustering k- means. Pada decision logout apakah admin ingin keluar dari program, jika tidak maka akan menampilkan halaman dashboard dan jika iya maka admin akan keluar dari halaman admin.

\subsection{Use Case Diagram}

Use case diagram ini digunakan untuk mengetahui fungsi apa saja yang ada di dalam sebuah sistem dan siapa saja yang dapat menggunakan fungsi-fungsi tersebut ditunjukkan seperti pada Gambar 3.5

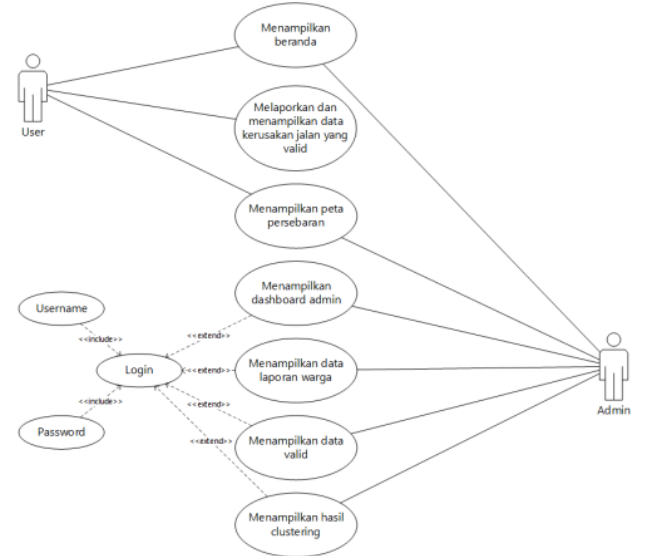

Gambar 3.5 Use case diagram

Berdasarkan use case diagram pada Gambar 3.5 user hanya dapat menampilkan beranda, menampilkan peta persebaran, melaporkan kerusakan jalan dan menampilkan data laporan kerusakan jalan yang sudah valid. Sedangkan admin dapat melakukan semua yang dilakukan user kecuali melaporkan kerusakan jalan. Admin dapat menampilkan dashboard admin, menampilkan semua laporan warga, menampilkan data kerusakan jalan yang sudah valid, dan menampilkan hasil clustering dengan ketentuan admin harus login system terlebih dahulu dengan input username dan password.

\subsection{Perancangan Database}

1. Tabel tb_admin, untuk menampung data admin yang ditunjukkan pada Tabel 3.1

Tabel 3.1 Tabel tb_admin

\begin{tabular}{|l|l|l|l|}
\hline No. & Nama Field & Tipe data & Keterangan \\
\hline 1. & id_admin & $\operatorname{int}(10)$ & Id admin \\
\hline 2. & username & $\operatorname{varchar}(100)$ & Username \\
\hline 3. & password & $\operatorname{varchar}(50)$ & Kata sandi \\
\hline
\end{tabular}

2. Tabel tb_lap, laporan berisi data laporan kerusakan jalan dari warga yang ditunjukkan pada Tabel 3.2.

Tabel 3.2 Tabel tb_lap

\begin{tabular}{|l|l|l|l|}
\hline No. & Nama Field & Tipe data & Keterangan \\
\hline 1. & id_laporan & $\operatorname{int}(100)$ & Id laporan \\
\hline 2. & pelapor & varchar(100) & Nama pelapor \\
\hline 3. & email & varchar(100) & Email pelapor \\
\hline 4. & telepon & varchar(100) & No telepon \\
\hline 5. & lokasi & varchar(100) & $\begin{array}{l}\text { Lokasi detail } \\
\text { kerusakan }\end{array}$ \\
\hline
\end{tabular}




\begin{tabular}{|l|l|l|l|}
\hline No. & Nama Field & Tipe data & Keterangan \\
\hline 6. & id_kecamatan & $\operatorname{int}(100)$ & Id kecamatan \\
\hline 7. & id_kerusakan & int(100) & Id kerusakan \\
\hline 8. & keterangan & varchar(100) & $\begin{array}{l}\text { Penjelasan } \\
\text { kerusakan }\end{array}$ \\
\hline 9. & tanggal & timestamp & $\begin{array}{l}\text { Tanggal } \\
\text { melaporkan }\end{array}$ \\
\hline 10. & latitude & varchar(100) & Titik koordinat \\
\hline 11. & longitude & varchar(100) & Titik koordinat \\
\hline 12. & gambar & varchar(100) & $\begin{array}{l}\text { Gambar } \\
\text { kerusakan }\end{array}$ \\
\hline 13. & status & varchar(100) & Status laporan \\
\hline
\end{tabular}

3. Tabel tb_valid, berisi data kerusakan jalan dari dinas bina marga kabupaten malang. Tabel tb_valid ditunjukkan pada Tabel 3.3.

Tabel 3.3 Tabel valid

\begin{tabular}{|l|l|l|l|}
\hline No. & Nama Field & Tipe data & Keterangan \\
\hline 1. & id_valid & $\operatorname{int}(100)$ & Id valid \\
\hline 2. & id_kecamatan & $\operatorname{int}(11)$ & Id kecamatan \\
\hline 3. & id_ruas & $\operatorname{int}(100)$ & Id ruas \\
\hline 4. & dari & varchar(100) & Awal km STA \\
\hline 5. & ke & varchar(100) & Akhir km STA \\
\hline 6. & lebar & $\operatorname{int}(100)$ & $\begin{array}{l}\text { Bobot lebar } \\
\text { kerusakan }\end{array}$ \\
\hline 7. & luas & $\operatorname{int}(100)$ & $\begin{array}{l}\text { Bobot luas } \\
\text { kerusakan }\end{array}$ \\
\hline 8. & id_kerusakan & $\operatorname{int}(100)$ & $\begin{array}{l}\text { Bobot jenis } \\
\text { kerusakan }\end{array}$ \\
\hline 9. & latitude & $\operatorname{varchar}(100)$ & Titik koordinat \\
\hline 10. & longitude & varchar(100) & Titik koordinar \\
\hline 11. & id_cluster & $\operatorname{int}(100)$ & Id cluster \\
\hline
\end{tabular}

4. Tabel tb_kecamatan, untuk menampung data kecamatan yang ditunjukkan pada Tabel 3.4

Tabel 3.4 Tabel tb_kecamatan

\begin{tabular}{|l|l|l|l|}
\hline No. & Nama Field & Tipe data & Keterangan \\
\hline 1. & id_kecamatan & $\operatorname{int}(100)$ & Id kec. \\
\hline 2. & kode & $\operatorname{varchar}(50)$ & Kode kec. \\
\hline 3. & nama_kecamatan & $\operatorname{varchar}(50)$ & Nama kec. \\
\hline
\end{tabular}

\section{HASIL DAN PEMBAHASAN}

\subsection{Perhitungan K-Means}

1. Menghitung jumlah data kerusakan jalan dari Dinas Bina Marga Kabupaten Malang terdapat 310 data yang ditunjukkan pada Tabel 4.1

Tabel 4.1 Data Kerusakan Jalan Kab. Malang

\begin{tabular}{|c|c|c|c|c|c|c|}
\hline No. & Kec. & Ruas & Dari-Ke & Lbr & Luas & Jns \\
\hline 1 & Lawang & $\begin{array}{c}\text { Lawang - } \\
\text { Sumberporong }\end{array}$ & $0-200$ & 1 & 1 & 1 \\
\hline 2 & Lawang & $\begin{array}{c}\text { Lawang - } \\
\text { Sumberporong }\end{array}$ & $200-400$ & 1 & 1 & 1 \\
\hline 3 & Lawang & $\begin{array}{c}\text { Lawang - } \\
\text { Sumberporong }\end{array}$ & $400-600$ & 1 & 1 & 1 \\
\hline$\cdot$ & & & & & & \\
\hline 310 & Dau & $\begin{array}{c}\text { Sumberrejo - } \\
\text { Petungsewu }\end{array}$ & $2,800-3000$ & 3 & 4 & 4 \\
\hline
\end{tabular}

Berdasarkan Tabel 4.1 dijelaskan bahwa terdapat 3 sample data kerusakan jalan yang terletak di Kecamatan Lawang pada ruas LawangSumberporong KM STA 0-600.
2. Menentukan jumlah cluster. Data kerusakan jalan dikelompokkan menjadi 3 cluster antara lain $\mathrm{C} 1$ = Ringan, $\mathrm{C} 2$ = Sedang, dan C3 = Berat.

3. Menentukan centroid awal

Tabel 4.2 Centroid awal

\begin{tabular}{|l|r|r|r|}
\hline & \multicolumn{1}{|l|}{ Lebar } & \multicolumn{1}{l|}{ Luas } & Jenis \\
\hline C 1 & 1 & 1 & 1 \\
\hline C 2 & 1.658064516 & 1.616129032 & 1.625806452 \\
\hline C 3 & 4 & 4 & 4 \\
\hline
\end{tabular}

4. Menghitung jarak euclidean. Perhitungan pada centroid tersebut dilakukan sebanyak data pada data kerusakan jalan dengan menggunakan rumus 2.1

Tabel 4.3 Jarak Euclidean

\begin{tabular}{|c|c|c|c|}
\hline $\begin{array}{c}\text { Data } \\
\text { Ke- }\end{array}$ & D(P1,C1 $)$ & $\mathbf{D}(\mathbf{P 2}, \mathbf{C} 2)$ & $\mathbf{D}(\mathbf{P 3 , C 3})$ \\
\hline 1 & 0 & 1.097404942 & 5.196152423 \\
\hline 2 & 0 & 1.097404942 & 5.196152423 \\
\hline 3 & 0 & 1.097404942 & 5.196152423 \\
\hline$\cdot$ & & & \\
$\cdot$ & & & 1 \\
\hline 310 & 4.69041576 & 3.622212948 & \\
\hline
\end{tabular}

5. Mengelompokkan data sesuai cluster berdasarkan jarak terpendek. Adanya perbandingan antara data $\mathrm{c} 1$, c2, dan c3 dapat dilihat data mana yang paling kecil maka masuk pada cluster tersebut.

Tabel 4.4 Hasil iterasi 1

\begin{tabular}{|c|c|c|c|c|}
\hline $\begin{array}{c}\text { Data } \\
\text { Ke- }\end{array}$ & $\mathbf{D}(\mathbf{P 1 , C 1})$ & $\mathbf{D}(\mathbf{P 2 , C})$ & $\mathbf{D}(\mathbf{P 3 , C 3})$ & $\mathbf{C}$ \\
\hline 1 & 0 & 1.097404942 & 5.196152423 & 1 \\
\hline 2 & 0 & 1.097404942 & 5.196152423 & 1 \\
\hline 3 & 0 & 1.097404942 & 5.196152423 & 1 \\
\hline$\cdot$ & & & & \\
. & & & & \\
\hline 310 & 4.69041576 & 3.622212948 & 1 & 3 \\
\hline
\end{tabular}

6. Menghitung centroid baru.

Tabel 4.5 Centroid baru

\begin{tabular}{|l|c|c|c|}
\hline & Lebar & Luas & Jenis \\
\hline C 1 & 1 & 1 & 1 \\
\hline C 2 & 2.6666667 & 2.722222 & 2.055556 \\
\hline C 3 & 3.4507042 & 3.253521 & 3.464789 \\
\hline
\end{tabular}

Setelah nilai dari centroid baru diketahui, langkah selanjutnya menghitung jarak data dengan centroid baru menggunakan jarak euclidien dengan rumus 2.1. Apabila cluster berubah maka perlu dilakukan iterasi lagi sampai data setiap cluster sama.

\subsection{Halaman Beranda}

Halaman ini menampilkan informasi umum mengenai kabupaten malang yang merupakan tampilan awal ketika user menjalankan program, seperti pada Gambar 4.1 


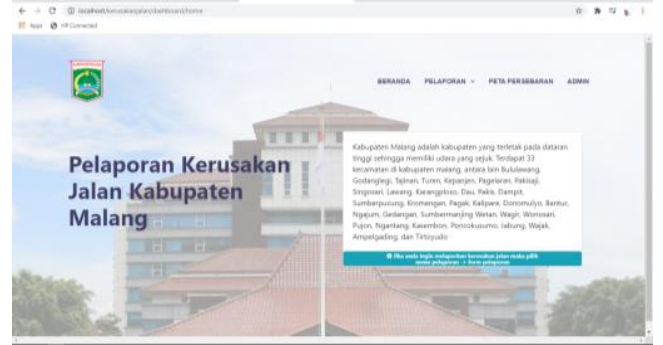

Gambar 4.1 Halaman beranda

\subsection{Halaman Peta Persebaran}

Halaman ini menampilkan data kerusakan jalan menggunakan marker dimana marker tersebut telah dilakukan proses clustering, seperti pada Gambar 4.2

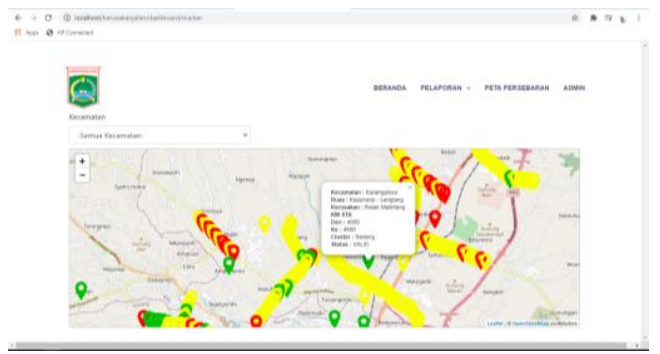

Gambar 4.2 Halaman peta persebaran

\subsection{Halaman Form Pelaporan}

Halaman ini menampilkan form tambah data pelaporan kerusakan jalan yang dilakukan oleh user/warga, seperti pada Gambar 4.3

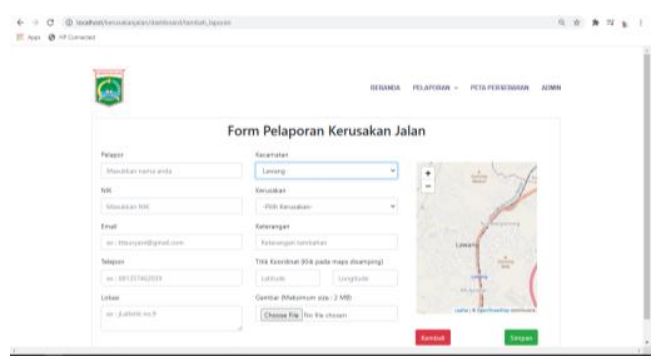

Gambar 4.3 Halaman form pelaporan

\subsection{Halaman Data Laporan Kerusakan Jalan}

Halaman ini menampilkan laporan yang lokasinya telah disurvey dan datanya dinyatakan valid oleh admin, seperti pada Gambar 4.4

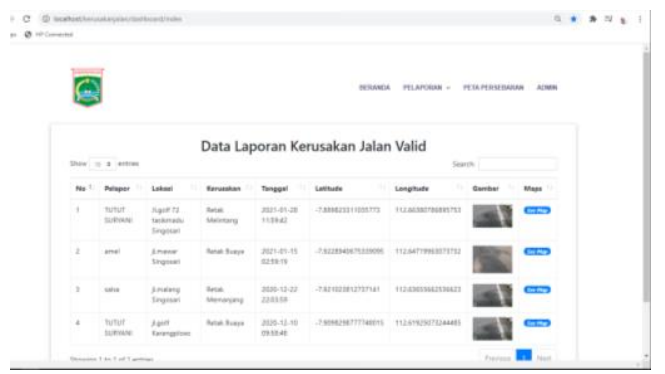

Gambar 4.4 Halaman data laporan kerusakan jalan

\subsection{Halaman Dashboard Admin}

Halaman ini menampilkan jumlah data cluster dan grafik clustering, seperti pada Gambar 4.6

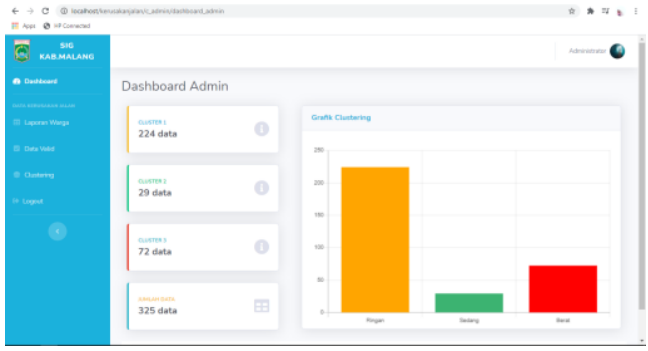

Gambar 4.6 Halaman dashboard admin

\subsection{Halaman Laporan Warga}

Halaman ini menampilkan semua laporan kerusakan jalan yang dilaporkan oleh user, seperti pada Gambar 4.7

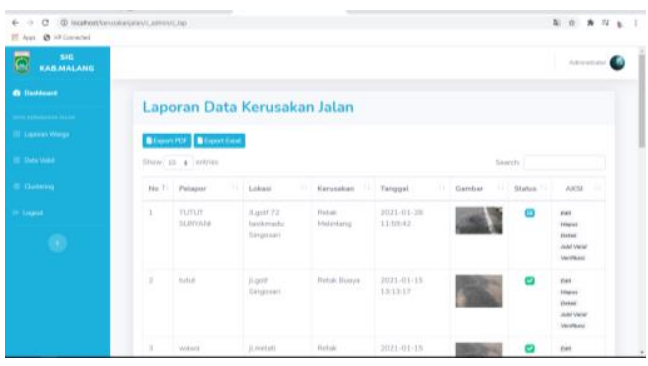

Gambar 4.7 Halaman laporan warga

\subsection{Halaman Clustering}

Halaman ini menampilkan data valid yang telah dilakukan proses clustering, seperti pada Gambar 4.9

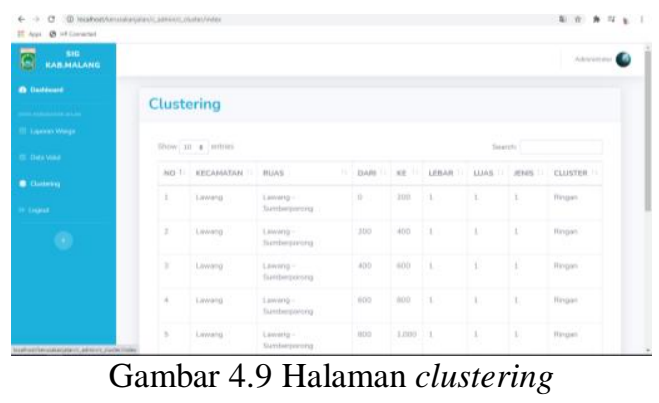

\subsection{Pengujian Akurasi Metode}

Pengujian akurasi metode ini menggunakan sebanyak 310 data yang didapatkan dari Dinas Bina Marga Kabupaten Malang dan dikelompokkan menjadi 3 cluster yaitu ringan, sedang dan berat. Untuk mendapatkan keterangan keakuratan hasil cluster dapat dilakukan perbandingan menurut Dinas Bina Marga dengan hasil pada aplikasi. Hasil perbandingan ditunjukkan pada Gambar 4.10 dan Gambar 4.11 


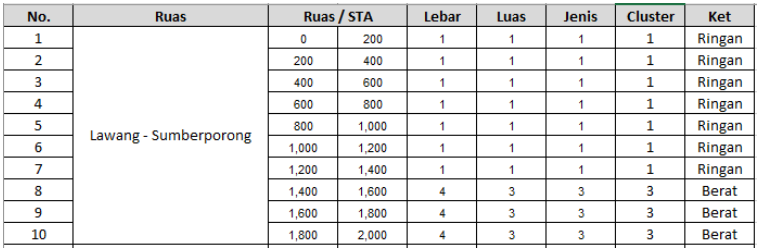

Gambar 4.10 Hasil dari Dinas Bina Marga

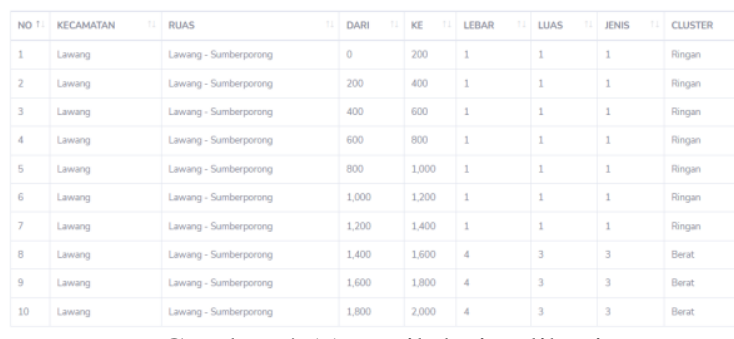

Gambar 4.11 Hasil dari aplikasi
Berdasarkan perbandingan menurut dinas bina marga dengan hasil pada aplikasi, maka persentase pengujiannya sebagai berikut :

Pengujian system $=\frac{\text { banyak hasil pengujian benar }}{\text { banyak data training }} \times 100 \%=\frac{310}{310} \times 100 \%=100 \%$

Hasil dari pengujian menunjukkan bahwa hasil dari bina marga dibandingkan dengan hasil pada aplikasi hasilnya sama, maka dapat disimpulkan bahwa metode k-means yang diterapkan pada website ini sudah tepat.

\subsection{Pengujian Metode Black Box}

Pengujian metode black box ini dilakukan dengan cara mengamati hasil running program untuk menguji fungsionalitas system berjalan sesuai dengan perancangan. Hasil pengujian black box dapat dilihat pada Tabel 4.1

Tabel 4.1 Pengujian Black Box

\begin{tabular}{|c|c|c|c|c|c|}
\hline No. & Skenario pengujian & Hasil yang diharapkan & $\begin{array}{c}\text { Hasil } \\
\text { pengujian }\end{array}$ & Kesimpulan & Teknik \\
\hline 1. & Klik navigasi maps & $\begin{array}{lr}\text { Sistem akan menampilkan } \\
\text { halaman maps disertai } & \text { marker } \\
\text { berwarna } & \text { yang } \\
\text { mengidentifikasikan } & \text { jenis } \\
\text { cluster } & \end{array}$ & $\begin{array}{c}\text { Sesuai } \\
\text { harapan }\end{array}$ & Berhasil & Performance \\
\hline 2. & $\begin{array}{l}\text { Klik combobox kecamatan } \\
\text { dan pilih kecamatan lawang }\end{array}$ & $\begin{array}{l}\text { Sistem akan menerima dan } \\
\text { menampilkan marker hanya } \\
\text { pada kecamatan lawang }\end{array}$ & $\begin{array}{l}\text { Sesuai } \\
\text { harapan }\end{array}$ & Berhasil & Performance \\
\hline 3. & $\begin{array}{l}\text { Klik navigasi report dan } \\
\text { pilih lapor }\end{array}$ & $\begin{array}{l}\text { Sistem akan menerima dan } \\
\text { menampilkan form tambah } \\
\text { laporan kerusakan jalan. }\end{array}$ & $\begin{array}{l}\text { Sesuai } \\
\text { harapan }\end{array}$ & Berhasil & Performance \\
\hline 4. & $\begin{array}{l}\text { Tidak mengisi data pelapor, } \\
\text { email, telepon, lokasi, } \\
\text { kecamatan, kerusakan, } \\
\text { keterangan, titik koordinat, } \\
\text { dan gambar kemudian klik } \\
\text { button simpan }\end{array}$ & $\begin{array}{l}\text { Sistem akan menolak dan } \\
\text { menampilkan pesan "please fill } \\
\text { out this field" }\end{array}$ & $\begin{array}{l}\text { Sesuai } \\
\text { Harapan }\end{array}$ & Berhasil & Robustness \\
\hline 5. & $\begin{array}{l}\text { Username dan password } \\
\text { tidak diisi kemudian diklik } \\
\text { button login }\end{array}$ & $\begin{array}{l}\text { Sistem akan menolak dan } \\
\text { menampilkan pesan "The } \\
\text { username field is required." dan } \\
\text { "The username field is } \\
\text { required." }\end{array}$ & $\begin{array}{l}\text { Sesuai } \\
\text { harapan }\end{array}$ & Berhasil & Robustness \\
\hline
\end{tabular}

Berdasarkan metode black box yang dilakukan terhadap system informasi geografis pemetaan kerusakan jalan di kabupaten malang ini dapat disimpulkan bahwa dalam pengujian tidak ditemukan kesalahan pada system dan hasil aplikasi sudah sesuai dengan perancangan.

\section{KESIMPULAN DAN SARAN}

\subsection{Kesimpulan}

Berdasarkan pengujian akurasi metode dan pengujian black box yang telah dilakukan pada system informasi geografis pemetaan keruskaan jalan ini dapat disimpulkan sebagai berikut :

1. Perbandingan hasil clustering k-means pada program dan Dinas Bina Marga sama-sama menunjukkan jumlah cluster $1(\mathrm{C} 1)=221$ data, cluster $2(\mathrm{C} 2)=24$ dan cluster $3(\mathrm{C} 3)=65$ data.

2. Hasil pengujian akurasi metode menunjukkan bahwa metode k-means yang diterapkan pada website ini sudah tepat dengan tingkat presentase kecocokannya $100 \%$.

3. Hasil pengujian metode black box untuk menguji fungsionalitas system berjalan baik dan dalam pengujian kesalahan pada system ditemukan sebesar $0 \%$

\subsection{Saran}

Berdasarkan penelitian yang telah dilakukan, maka penulis dapat memberikan saran-saran untuk pengembangan selanjutnya agar aplikasi ini berjalan dengan baik, antar lain : 
1. Menambahkan jenis kerusakan jalan, seperti jalan berlubang dan jalan amblas

2. Menggunakan metode lain untuk membandingkan tingkat keakuratannya.

3. Menambahkan data kerusakan jalan agar hasil semakin akurat.

4. Menambahkan notifikasi email pada user ketika status sudah valid, sudah diperbaiki maupun ketika status tidak valid.

\section{DAFTAR PUSTAKA}

[1] H. Mubarak, "Analisa Tingkat Kerusakan Perkerasan Jalan Dengan," Fakultas Teknik Universitas Abdurrab, Pekanbaru, Indonesia, vol. 16, no. 1, pp. 94-109, 2016.

[2] L. G. S. Handayani, I. N. Piarsa and K. S. Wibawa, "Sistem Informasi Geografis Pemetaan Jalan Desa," Jurusan Teknologi Informasi, Fakultas Teknik, Universitas Udayana, vol. 6, no. 2, pp. 128-137, 2015.

[3] D. Muryanto and R. S. , "Evaluasi Kerusakan Ruas Jalan Kalimas Baru Kota Surabaya Dengan Menggunakan Metode Bina Marga," Prodi Teknik Sipil, Universitas Dr. Soetomo, vol. 7, no. 1, pp. 24-30, 2019.

[4] M. S. Lauryn and M. Ibrohim, "Sistem Informasi Geografis Tingkat Kerusakan Ruas Jalan Berbasis Web," Jurnal Sistem Informasi, vol. 6, no. 1, pp. 20-31, 2019.

[5] K. Auliasari and Sukmadiningtyas, "Penerapan Pemodelan Spasial pada Sistem Informasi GeografisTenaga Kesehatan Kabupaten Malang," Jurnal MATICS, vol. 8, no. 1, pp. 7-10, 2016.

[6] M. G. Sadewo, A. P. Windarto and A. Wanto, "Penerapan Algoritma Clustering Dalam Mengelompokkan Banyaknya Desa/kelurahan
Menurut Upaya Antisipasi/Mitigasi Bencana Alam Menurut Provinsi Dengan Kmeans," KOMIK (Konferensi Nasional Teknologi Informasi dan Komputer), vol. 2, no. 1, pp. 311319, 2018.

[7] K. M. Wibowo, I. Kanedi and J. Jumadi, "Sistem Informasi Geografis (SIG) Menentukan Lokasi Pertambangan Batu Bara Di Provinsi Bengkulu Berbasis Website," Jurnal Media Infotama, vol. 11, no. 1, pp. 51-60, 2015.

[8] A. Syafrianto, "Perancangan Aplikasi K-Means Untuk Pengelompokan Mahasiswa STMIK ELRAHMA Yogyakarta Berdasarkan Frekuensi Kunjungan Ke Perpustakaan dan IPK," STMIK EL RAHMA, 2012.

[9] R. P. I. J. M. (RPIJM), "Gambaran Umum dan Kondisi Wilayah Kabupaten Malang," 2015. [Online]. [Accessed 2020].

[10] P. B. M. (Perbup), "UPT Pemeliharaan Jalan Bina Marga," 2017. [Online]. [Accessed 2020].

[11] B. P. P. D. (BAPPEDA), "Tentang Peta dan Pemetaan," 12 Juni 2013. [Online]. Available: https://bappeda.grobogan.go.id/berita/serbaserbi/112-tentang-peta-dan-pemetaan. [Accessed 2020].

[12] U. Hanifah, R. Alit and Sugiarto, "Box, Penggunaan Metode Black Pada Pengujian Sistem Informasi Surat Keluar Masuk," Teknik Informatika Fakultas Teknologi Industri Universitas Pembangunan Nasional "Veteran", vol. XI, no. 2, pp. 33-40, 2016. 